\title{
On Pluralism and Conceptual Engineering: Introduction and Overview
}

Delia Belleri

LanCog, Centre of Philosophy, University of Lisbon

bellerid@edu.ulisboa.pt

In Inquiry: An Interdisciplinary Journal of Philosophy. Published version available at the following link: https://doi.org/10.1080/0020174X.2021.1983457

\begin{abstract}
Pluralism is relevant to conceptual engineering in many ways. First of all, we face the issue of pluralism when trying to characterise the very object(s) of conceptual engineering. Is it just concepts? Could concepts be pluralistically conceived for the purposes of conceptual engineering? Or rather, is it concepts and other representational devices as well? Second, one may wonder whether concepts have only one function in our mental life (representation) or, rather, a plurality of functions (including non-representational ones). Third, it is a contended question whether conceptual engineering projects should pursue only one set of values and goals (epistemic ones) or, rather, a variety of values and goals, including non-epistemic ones. Finally, the engineering of a concept may result in a form of "local" conceptual pluralism, which gives rise to its own ontological and semantic challenges. Having explored the various ways in which pluralism becomes important for conceptual engineers, this contribution presents and summarizes the articles published in this special issue.
\end{abstract}

Key words: conceptual engineering, pluralism, concept function, values and goals, change of subject 


\section{Opening remarks}

In the last few years, analytic philosophy has witnessed a surge of interest in projects of conceptual engineering, and in methodological reflections about them. Conceptual engineering may be described as a philosophical methodology that focusses on the assessment and revision of conceptual representations. The core ideas that motivate conceptual engineering are, as far as I can see, two. First, our concepts are not necessarily perfect, and may sometimes use improvements. Second, these improvements cannot be achieved via descriptive tasks of conceptual analysis; philosopher should, when possible, make a concerted effort to propose and advocate new, or revised, conceptual resources.

Conceptual engineering projects are normatively charged endeavours. Potentially defective concepts are assessed relative to specific criteria. Revisions are often proposed based on the function that a concept is supposed to serve. Engineering proposals pursue particular aims and goals, and strive to promote specific values and goods. At the end of this process, we might find ourselves with a plurality of concepts, whose mutual relationship needs to be understood and regulated.

In this scenario, it is difficult to ignore questions like: "Is there one criterion for evaluating a concept, or are there many criteria?", "Do concepts have one essential function, or do they have many?", "Is there a single overarching goal, value or good that should be promoted in conceptual revision? Or is there a plurality of goals, values and goods?". Another pressing question has to do with a possible outcome of conceptual engineering: "When the revision produces multiple conceptual representations, how should these representations relate to each other?". These questions suggest the importance of starting a conversation on the relevance of pluralism in conceptual engineering.

The need for such a conversation appears even more urgent if we consider that conceptual engineering is often associated with the idea of conceptual ethics. As Alexis Burgess and David Plunkett characterise it, conceptual ethics deals with "normative and evaluative issues about thought and talk" (Burgess and Plunkett 2013, p. 1095; see also Burgess and Plunkett 2020; McPherson and Plunkett 2020; Cappelen and Plunkett 2020). It 
is an inquiry into what makes something a good concept, which concepts are good or bad, which concepts we should use and which ones we should refrain from using. Given the centrality of normative and evaluative considerations in conceptual ethics, here too it seems natural to ask about matters of pluralism. Is there only one way of being a good concept, or are there many? Is there only one order of considerations regarding which concepts we should use, or are there many? Burgess and Plunkett (2013, p. 1104) seem to favour a pluralistic view, as they acknowledge that different conceptual engineering projects promote different values and goods, such as consistency and coherence, objective naturalness (or "joint-carving"), ideological parsimony, as well as social justice. Yet, as we shall see, antithetic views have been proposed.

The aim of this introduction is twofold. First, it offers an overview of the general questions that arise when conceptual engineering meets the issue of pluralism. Second, it introduces and summarizes the contributions published in this special issue, focussing on their relation to the aforementioned general questions. Accordingly, section 2 is devoted to pluralism about the objects of conceptual engineering. Section 3 delves into pluralism about the function of concepts, and its impact on conceptual engineering. Section 4 explores pluralism about the goals and values to be pursued in conceptual engineering. Section 5 considers scenarios in which conceptual engineering gives rise to multiple alternative concepts, and the challenges that emerge in such circumstances. Section 6 presents the articles published in this special issue.

\section{Pluralism about the objects of conceptual engineering}

What are the objects of conceptual engineering? The natural response would seem to be: concepts. Yet, what are concepts? Or - more relevantly - how should we conceive of concepts for the purpose of conceptual engineering?

Some theorists choose to sidestep the question. Herman Cappelen adopts a simplified account, which he calls "Austerity Framework", that avoids positing concepts qua philosophical or psychological entities, and works on the assumption that "what 
changes when we engage in conceptual engineering are extensions and intensions of expressions" (2018, p. 53). If conceptual engineering is conceived as being just about words' extensions and intensions, all the open questions regarding the nature and structure of concepts can be circumvented.

Other authors explicitly adopt a pluralist approach. Manuel Gustavo Isaac, for example, suggests that "[f]or the purposes of conceptual engineering, concepts should [...] be construed as multiply realizable functional kinds" (p. 8). According to this view, concepts perform specific causal or explanatory functions in higher cognitive processes, such as abstraction, categorization, induction, and so on. The core of the proposal is that concepts are realizable by several different basic kinds, such as exemplars, prototypes, or theories. Isaac maintains that his proposal would achieve and justify "the maximum scope for the method of conceptual engineering on the world of our everyday life" (Isaac 2020, p. 8). This means that, if one wants to embark in a conceptual engineering project, one need not exclusively focus on intensions and extensions; rather, one has a chance to focus on other cognitive structures that play pivotal roles in our mental lives. Focussing on these cognitive aspects would help one better design and implement a conceptual revision, as it would ensure a more psychologically accurate approach to the revisionary enterprise. A detailed overview of the benefits and limitations of working with concepts cashed out as definitions, prototypes, exemplars, theories, or multimodal devices is offered by Ryan Neftd (2021).

There is another option: one may surmise that the objects of conceptual engineering are not just concepts - whatever their nature turns out to be -, but representational devices at large. Conceptual engineering may therefore focus on other types of representations. Cappelen and Plunkett mention lexical items and their meanings (Cappelen and Plunkett 2020, p. 3; see also Burgess Plunkett 2020, p. 5). Other objects could be added, based on recent proposals. David Chalmers considers theses. In his view, "[e]ven when philosophy involves new concepts, it typically also involves new theses involving those concepts" (Chalmers 2020, p. 13). Concepts are not engineered for their own sake, but rather for the potential, new insights they allow to express. Mark Richard (2020) has it that interesting 
examples of conceptual engineering are, oftentimes, about revising the presuppositions associated with a concept, rather than about the concept's extension. The conceptual engineer aims to enter new or different presuppositions into the speakers' common ground, so that the use of a word, as well as the descriptions one associates with it, spread like "genes within a population". For Kevin Scharp (2013), conceptual engineering can involve revising a concept's constitutive principles; indeed, he proposes to overcome alethic paradoxes by outlining two, different concepts of truth, which respond each to different constitutive principles. Vera Flocke (2020) suggests that engineering a concept consists in changing the rules that speakers use to evaluate the truth of certain propositions. For instance, engineering the concept TORTURE means changing the rules speakers appeal to in determining whether it is true that a certain practice (e.g., waterboarding) is torture. Other possible objects of conceptual engineering include beliefs, theories, conceptions and topics.

One risk for this option is that it returns a ragbag of objects that have too little in common. A unifying strategy is needed. Such strategy is offered by Mirela Fuš (2021), who suggests that something can be the object of a conceptual engineering project as soon as it becomes of philosophical interest. This unifying feature, "being philosophical", allows Fuš to maintain a very permissive form of pluralism, whereby the category "objects of conceptual engineering" can encompass both entities that are the focus of current projects as well as entities that might become the focus of possible projects.

\section{Pluralism about the function of concepts}

What are concepts for, in our mental life? There is a tendency, at least in analytic philosophy, to think that concepts only, or ultimately, have a representational function. Call this view function monism. Some authors talk of concepts as "carving the world at its joints" (Sider 2011) or as picking out natural properties, that is, properties that belong to the fundamental level of reality (Lewis 1983). Following this line of thought, it seems like conceptual engineering should only aim at achieving representations that better fit, or better correspond to, reality. Someone could even argue that, if an instance of conceptual 
engineering were to enhance other aspects of a concept, while leaving its representational function unchanged, it may not count as a genuine case of conceptual engineering.

Yet, concepts can be conceived as having a plurality of other important functions in our mental life. Concepts organize information that is stored in our memory; they enable categorisation; they facilitate reasoning, prediction, and explanation. We could call these the "cognitive functions" and the "theoretical functions" of concepts. Furthermore, they are involved in evaluative judgments, decision-making, action guiding and inter-subjective coordination. Let these be the "practical functions" of concepts. This list suggests that a pluralistic approach to the function of concepts (call it function pluralism) is available. Some examples of function pluralism are supplied by Amie Thomasson (2020, p. 448): as she observes, mathematical concepts and terms do not just serve the function of "tracking" numbers and their relations (if there are any at all); they also allow us to simplify our statements of laws. Moral concepts and terms do not just represent moral facts (if there are any at all); they enable attitude expression and inter-subjective coordination. Also in a pluralist spirit, Jennifer Nado urges that we "decline to identify some central, or proper, or essential function" (2019, p. 15) for concepts; rather, functions can be multiplied if we think of them as extrinsic properties of concepts - as "what we use concepts for". If such functional pluralism were true, we would have good reasons to think that conceptual engineering should not only improve on representational joint-carving; rather, it could and should, where appropriate, aim to improve on these other aspects (see Pérez Carballo 2020).

An interesting question has to do with how function pluralism should be outlined. Some may insist that the representational function is the most fundamental one, without which neither the cognitive, nor the theoretical, nor the practical functions could be fulfilled. We may call this hierarchical function pluralism. This may have repercussions on the issue of which functions should be more cherished as opposed to which functions are more expendable in revision processes. One may hold that revisions that alter the 
representational function of a concept to a degree considered excessive may be deemed undesirable, even if they enhanced other important functions of that concept.

This point has been recently made by Mona Simion (2018a). Her view is that even though concepts may indeed have many functions, the primary function of concepts is representational. For example, the concept WOMAN has the function of representing women, by referring to them. Consider now Sally Haslanger's proposed engineering, whereby women are defined (roughly) as individuals subordinated on account of their biological sex. If we apply this new concept, some individuals who are female, but not subordinated, do not count as women. Yet they are, intuitively, women. In Simion's view, this implies that the representational function of the concept is compromised. More importantly, the alleged political benefits advertised by Haslanger do not, according to Simion, make up for the damaging of the representational function. This is because any political function played by the concept "rides on" its representational function: "If one engineers 'woman' for political gain, and thereby the concept loses its representational epistemic function, it also loses its political significance" (Simion 2018a, p. 97). Thus, we may identify Simion as maintaining a hierarchical pluralism about concept function where the representational function takes priority because it should, at the very least, be left unchanged (if not outright improved).

Alternatively, one may hold that all such functions are on a par. We may call this an equal-level function pluralism. As a consequence of this view, revisions that imply significant changes in the representational function of a concept need not be considered objectively less desirable than revisions that imply no such changes. They may, therefore, be selected according to specific, context-related needs and purposes. Yet another alternative may be that these functions cannot be compared - so we can neither say that they are hierarchically related, nor that they are on a par. Let us call this position silent function pluralism. This would entail that there is no objective fact of the matter as to the mutual relation between competing conceptual revisions. Selecting one revision rather than 
another might therefore be motivated solely by specific, context-related needs and purposes.

Both the "equal-level" and the "silent" varieties of function pluralism appear to be compatible with the normative approach to concept revision defended by Esa Díaz-León (2020). In her view, we might use normative considerations to "break ties" when it comes to assessing candidate revisions for a certain concept that seem to be on a par. Consider again the concept WOMAN. Ordinarily, it is spelled out as "human adult female". Haslanger proposes: "individual subordinated based on their female sex". Katharine Jenkins (2016) proposes yet another revision, in terms of (roughly) "individual who identifies as a woman". None of these candidates is more joint-carving. Furthermore, each of these candidates carves up the set of women in different ways, some more familiar than others, but all in some sense useful and motivated. In this situation, how to decide which concept should be expressed by the word "woman"? According to Díaz-León, we can "appeal to the relevant moral and political reasons in the vicinity in order to decide which candidate meaning should be the meaning of that term (if any)" (2020, p. 180). Relevant guiding considerations have to do with fighting gender oppression, increasing inclusivity, and so on. This proposal would seem compatible with both "equal-level" and "silent" pluralism to the extent that normative considerations could play the role of the contextrelated reasons for adjudicating a certain revision, in the absence of objective, guiding criteria.

\section{Pluralism about the goals and values of conceptual revisions}

Conceptual engineering projects always aim at achieving certain goals. In turn, these goals are value-laden; they are pursued because they promote values that are deemed important. Generally, it is possible to clearly distinguish a project's goal from the values it pursues. Yet, nothing forbids that, on other occasions, the value just is the goal. Think of a lawmaker who revises the concept MARRIAGE so that it includes same-sex unions. The goal is to broaden the extension of the concept to include same-sex couples. The values that inform 
this goal have to do with equality and social justice. Yet, it seems that the values of equality and social justice can also be identified as goals in themselves. Our talk of values seems to license describing values as goals; thus, talk of goals and talk of values may sometimes be difficult to disentangle. ${ }^{1}$

Consider now the general question of the goal for which concepts are used in our mental life. There is a tendency to think that knowledge, or truth, are the only, or the ultimate goals served by our use of concepts in our mental life. Presumably, knowledge and truth are goals because they are values too; more specifically, epistemic values (or "epistemic goods") to be pursued in our mental lives and in our inquiries.

From this picture, it seems to follow that the only goal of a conceptual engineering project should be an increase of knowledge. We may dub this view goal monism for conceptual engineering. Since goals and values are tightly related, we may suppose that goal monism goes hand in hand with value monism for conceptual engineering, the view that the only value to be pursued by conceptual engineering project is knowledge, or truth. Both views look quite radical, since they would imply that, if a conceptual revision does not cause an increase of knowledge - and, rather, leaves our knowledge just as it is - then it should not be performed; or, if it is performed, it is not an instance of bona fide conceptual engineering.

In contrast with goal monism, one could draw attention to the many "cognitive goals" and "theoretical goals" we pursue when using concepts - including categorization, acquiring beliefs through deductive and inductive reasoning, finding explanations, making predictions, reading others' intentions, and so on. These need not be epistemic goals narrowly construed, since they may not involve knowledge or truth; for instance, a category may be cognitively fruitful even though it fails to capture "real" distinctions. Yet, pursuing these goals may help humans make progress in, for instance, science and technology:

\footnotetext{
${ }^{1}$ Indeed, Alexis Burgess and David Plunkett (2013, p. 1105) tackle the question whether goals should be reduced to values (which they also call "goods"). In response, they suggest that values (or "goods") are in some sense superior to goals, because goals could be self-serving and opportunistic, while values (or "goods") do not typically lend themselves to such exploitation.
} 
indeed, as Ingo Brigandt's (2010) study of the concept GENE shows, a concept could be used to achieve different broadly construed "epistemic goals", such as different explanatory or predictive tasks, within a process of inquiry. Furthermore, a range of "practical goals" for concepts could be countenanced, including evaluation, deliberation, action, and intersubjective coordination.

Pluralism about the goals that concepts serve in our mental life appears therefore plausible. This, in turn, would imply that conceptual engineers could pursue a host of goals, both epistemic and non-epistemic, when proposing conceptual revisions. Call this view goal pluralism for conceptual engineering. We may surmise that goal pluralism goes hand in hand with value pluralism for conceptual engineering (as already noted by Burgess and Plunkett 2013, p. 1104). The values attached to the goals just listed may include, on the cognitive side, representational adequacy (to be spelled out in terms of explanatory fruitfulness, simplicity, parsimony and so on), and, on the practical side, applicability, implementability, justice, fairness, equitability, utility, and so on.

Goal pluralism may be articulated in different ways. A goal pluralist could contend that some goals are more valuable than others. For instance, she may hold that truth and knowledge are the primary goals to be aimed at when performing a conceptual revision. All other goals are subordinated; they may be pursued only if they do not impinge on the primary goals. Call this position hierarchical goal pluralism.

In recent work, Mona Simion articulates a view compatible with this type of pluralism. Simion's (2018b) central claim is that "a concept should be ameliorated only insofar as this does not translate into epistemic loss" (p. 10). The main goal for the conceptual engineer should be improving, or at the very least not worsening, our epistemic situation. Simion considers the following example: our current concept DEER refers to fallow deer, red deer, roe deer and muntjac deer. Suppose roe deer was, for natural reasons, more vulnerable than the other sub-species of deer, and that this made roe deer more likely to be killed by hunters. We could revise the concept DEER to exclude roe deer from the concept's extension in hunting regulations, thus protecting them from humans. This would 
help attain the ethical goal of saving an endangered species. Yet, as a consequence, members of the linguistic community would lose knowledge about deer, because sentences like "Roe deer are deer" or "This is a deer" (uttered while pointing at a roe deer) would now be false. By Simion's lights, if a conceptual revision results in concept-users having less knowledge about the world than they had prior to the revision, then one should not go for it; or, if one does, one does not really ameliorate the concept. I consider this example illustrative of a hierarchical type of pluralism, because Simion envisages the possibility of pursuing non-epistemic goals. Yet, she still considers these goals to be secondary because, if pursuing these goals were to involve an epistemic loss, the engineering project would be judged unsuccessful.

In a recent response to Simion, Paul-Mikhail Podosky (2018) argues that, at least on some occasions, revisions that imply an epistemic loss are admissible, if this epistemic loss is temporary and "lays the ground" for the construction of a new conceptual system (also called "ideology") that can causally affect reality so as to make itself accurate, and therefore knowledge-conducive. Thus, in the case of Haslanger's revised concept WOMAN, speakers would suffer a temporary loss of knowledge because their beliefs about some nonsubordinated females may become false. Yet, this is okay - Podosky holds - because this is only a temporary phase. If the proposed revision becomes sufficiently widespread, it will affect what gender itself is through a process of reinforcement. This will result in a new conceptual system (or "ideology") by means of which to describe reality and to acquire knowledge. I take this proposal to still subscribe to hierarchical goal pluralism, since it deems epistemic losses admissible only if knowledge can be "reinstated" in the successor conceptual system (or "ideology"), thus still granting the primacy of knowledge.

One could oppose this hierarchical insight by holding that all goals (epistemic and non-epistemic) are equally valuable. Since there is no objective ranking of goals, choosing to pursue one goal rather than another may be motivated by contingent, contextual reasons. This view may be dubbed equal-value goal pluralism. As an alternative, one could embrace the view that there is no fact of the matter as to whether goals are hierarchically 
arranged or on a par. Their mutual relation must be settled case-by-case, based on particular, context-relative considerations. This position may be identified as a silent goal pluralism.

Both positions appear compatible with a recent proposal advanced by Manuel Gustavo Isaac (2021), in reaction to Podosky's move. Isaac questions the priority of the epistemic and depicts the goals of conceptual engineering projects as being extremely adaptable to contextual considerations. In some contexts, achieving certain ethical goals could matter more than preserving the concept's epistemic function. Relative to the purposes at stake in those contexts, we should be allowed to revise concepts so that they meet the relevant desiderata. This pluralistic attitude with respect to goals may result in a plurality of engineered concepts. In the case of deer, for instance, Isaac envisages the possibility of constructing differ deer-concepts depending on the different purposes at stake. If the purpose at stake is ethical, then one revision may be effected and implemented in one set of contexts; in other contexts, where the ethical considerations are not prominent, the ordinary concept of deer (with its ordinary taxonomic function) may still fit the bill. I take Isaac's approach to be compatible with both "equal-value" and "silent" goal pluralism to the extent that, in both kinds of pluralisms, particular, context-related considerations can play a pivotal role in steering the engineer's revisionary efforts.

Thus far in this section, our attention has been focussed on varieties of goal pluralism for conceptual engineering. Yet, one could presume that the same variety of pluralisms can affect conceptual engineering's values. Some theorists could believe in a hierarchy of values (hierarchical value pluralism); other may consider these values to be on a par (equal-value value pluralism); yet others may suggest that there is no fact of the matter as to the mutual relation between values (silent value pluralism). Space limitations prevent a detailed examination of these options, which, at any rate, provide interesting material for future investigation.

There are further stimulating questions to be explored in connection with value pluralism. Suppose one admits that conceptual engineering projects can pursue different 
values - whether these values are ranked, or all on the same level, or whether there is no fact of the matter. The following question may still be asked: "Do all these values contribute to an overarching value, in terms of which they can all be spelled out?". Say that this overarching value is "being a good concept". If a concept gets ameliorated epistemically, does that mean that progress has been made with respect to how "good" that concept is, by intervening on how "epistemically good" it is? If the concept undergoes an ethical amelioration, have we made progress on how "good" that concept is, by improving on how "ethically good" it is? Answering these questions would, at the very least, help us understand better our own criteria of evaluation for concepts.

\section{When conceptual engineering creates a plurality of concepts}

A plurality of concepts may be the result of a conceptual engineering project. This may happen because revision may not lead to a complete replacement of the old concept with the new one (or the new ones). The old concept and the new one(s) might continue to exist together. In these cases, the result would be a form of "local" conceptual pluralism.

Forms of "local" conceptual pluralism are not uncommon in science and philosophy. In science, well-known examples of conceptual pluralism resulting from what we may think of as long-term, collective engineering efforts involve the concepts of mass, gene, and planet - to mention but a few popular case studies. These are cases in which scientific progress has caused a juxtaposition of concepts belonging to pre-existing theories on the one hand, and of newer concepts on the other, resulting in the coexistence of different representations.

In analytic philosophy, some proposed conceptual revisions might also potentially give rise to a juxtaposition of older and newer concepts, thus creating a de facto pluralism. For instance, Sally Haslanger's amelioration of WOMAN may be conceived as a revision that adds a new representational tool for thinking and talking about women (at least initially, in the context of feminist and anti-racist theorizing), while the ordinary concept of woman is still around and "competes" with this new representational device. One could 
venture a similar interpretation for the work of authors who introduced new definitions of a certain concept into the relevant discussion, thus bringing about contenders for the preexisting conceptual representations: for example, Harry Frankfurt on free will, Edward Craig on knowledge, James Woodward on causation, Ted Sider on existence, to name but a few.

In some cases, the engineering endeavour appears to "split" a pre-existing concept into a variety of conceptual representations; the plurality of representational devices resulting from the splitting is supposed, at least ideally, to replace the pre-existing concept, on account of its greater theoretical advantages. Whether the replacement succeeds or not, conceptual pluralism ensues. Think of Kevin Scharp's (2013) replacement of the truth concept with the concepts ASCENDING-TRUTH and DESCENDING TRUTH. At least for theoretical purposes, these two concepts are supposed to supplant the old truth concept because, unlike the latter, they do not give rise to inconsistencies. Scharp is not interested in a large-scale replacement. Still, irrespectively of whether such large-scale replacement is feasible or will ever happen, his proposal creates a situation of conceptual pluralism. Other authors in the history of analytic philosophy may be interpreted as giving rise to similar forms of pluralism: think, for instance, of Crispin Wright's (1992) pluralism about truth; or of William Alston's (2005) pluralism about epistemic desiderata. Further, very recent proposals may be read as articulating multiple concepts of, for instance, disagreement (MacFarlane 2014), knowledge (McKenna 2017) or grounding (Richardson 2020). In fairness to these authors, I should stress that I am suggesting an interpretation of their writings in terms of conceptual engineering. They may describe their work as being about kinds, properties, relations, or predicates. Still, an interpretation in terms of conceptual engineering seems sufficiently harmless, in that it is certainly arguable that conceptual revisions or innovations are introduced in the process of articulating these first-order views about kinds, properties, relations, or predicates.

In a recent article, Ingo Brigandt and Esther Rosario (2020) explore the methodology of purposefully revising a pre-existing concept in a pluralistic way. 
Considering that a concept may serve several epistemic and non-epistemic aims, Brigandt and Rosario propose to engineer concepts "strategically", designing different conceptual representations to meet different aims. They illustrate this with the concept GENDER. The

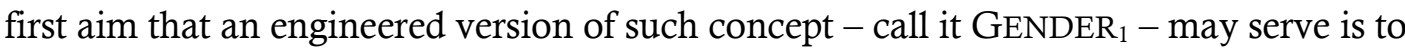
identify and explain gender-based discrimination. In the same spirit as Sally Haslanger's ameliorative analysis, Brigandt and Rosario propose a "relational" concept of gender which might capture aspects of discrimination tied to intersectionality. The second aim is to assign legal rights and ensure gender-appropriate social recognition. Inspired by the proposal set forward by Katharine Jenkins (2016), Brigandt and Rosario suggest a gender concept - call it GENDER 2 - whereby a subject's belief that, for example, "she belongs to the gender category termed woman" (p. 118), suffices for her to be recognized as a woman, without requiring further knowledge of gender-specific expectations (contra Jenkins' characterization). The third aim is to empower persons by means of their gender identity. For Brigandt and Rosario, a concept tailored to this aim - call it GENDER ${ }_{3}$ - should be suggestive of the "positive affordances" associated with each gender, to permit the empowerment of subjects based on their gender identification.

If a conceptual engineering process gives rise to a variety of conceptual representations, the resulting pluralism can present the theorist with several challenging questions. The first question has to do with the mutual relation that obtains between the alternative concepts. Are these concepts all compatible with one another, perhaps because they each illuminate one aspect of the object they refer to? Call this view tolerant conceptual pluralism. If this account were true, then there would seem to be a "common denominator" to the various concepts resulting from the engineering endeavour. Consider, for instance, Brigandt and Rosario's suggestion: according to this tolerant option, the concepts GENDER $_{1}$, GENDER$_{2}$, and GENDER 3 would all have to do with gender. Yet, what is gender? Is it denoted by a single, overarching GENDER concept? How could this overarching concept be characterised? An alternative view is that these concepts are in competition with each other, since only one of them can correctly represent the object under examination - 
or denote the right object(s). Call this view intolerant conceptual pluralism. This would imply, for instance, that only one between GENDER ${ }_{1}, G_{E N D E R}$, and GENDER 3 is the genuine concept of gender. The other concepts do not describe what gender is. The question is, then: what do they describe? And why did we feel it was okay to identify all of them as gender concepts? A final alternative is that these concepts are insulated from one another, each characterizing or denoting a separate portion of reality. Call this option indifferent conceptual pluralism. In the case of GENDER ${ }_{1}$, GENDER 2 , and GENDER ${ }_{3}$, however, one might ask: why did we feel it was correct to characterise them as gender concepts? Why would one think that they are semantically disconnected from one another?

Another challenging question that might arise in a scenario of conceptual pluralism brought about by a conceptual engineering process has to do with the so-called "change of subject objection" (see Cappelen 2018 and Pinder 2019, who link this objection to a famous criticism that Peter F. Strawson (1963) raised for Carnapian explication). Do the newly introduced concepts imply a change in the subject of inquiry or of conversation? Do the speakers who embrace the newly engineered concepts cause communication disruptions (in the form of, for instance, merely verbal disputes) with the speakers who are still employing the old concept? Several options become available at this point. Herman Cappelen (2018) would argue that the various concepts resulting from an engineering effort need not cause a change of subject, as long as they all concern the same topic - where topic is a way of representing what an expression is about that is more coarse-grained than intension and extension. Other theorists emphasize the function of concepts and maintain that, as long as the revised representational device performs the same function, engineering concepts does not yield conceptual representations that change the subject (see Prinzing 2017, Simion and Kelp 2020, Thomasson 2020, Haslanger 2020). For some externalist authors, such as Sarah Sawyer (2020), as long as the newly engineered concepts refer, by means of externalist mechanisms, to the same object, continuity in topic is secured. This would be the case even if the revision had brought different speakers to have diverging beliefs (for Sawyer, "conceptions") about that object. Alternative approaches (Belleri 2021, Knoll forthcoming- 
a) have it that it is okay to change the subject. For Knoll, changing the subject for the better should, in fact, be one of the main goals of conceptual engineering. For Belleri, subjectchange is sustainable as long as it is possible to connect the pre-existing concept and the newly introduced one(s) at the metalinguistic or metaconceptual level, for example in terms of causal, or spatio-temporal continuity. This may help one spot, and remedy, communication breakdowns within an inquiry or a conversation.

\section{Contributions in this volume}

Each of the papers published in this special issue sheds new light on the connection between pluralism and conceptual engineering. The reader will find new insights on the metaphysics and metasemantics of concepts; on the mutual relation between subordinate and superordinate concepts in a pluralistic setting; and on the connection between prerevision and post-revision concepts in communication. Furthermore, two engineering projects giving rise to forms of local conceptual pluralism will be presented, concerning the concepts KNOWLEDGE and EXISTENCE respectively. The following summaries highlight the connection between the issues presented in previous sections and each contribution's topic; the order of presentation reflects the order in which the previous issues were surveyed.

Sarah Sawyer's contribution, entitled "Concept Pluralism in Conceptual Engineering" (Sawyer forthcoming), provides an unprecedented taxonomy of concepts for the purposes of conceptual engineering. Sawyer sharpens the externalist metasemantic idea that a concept's content is at least partly determined by external, causally relevant factors, by canvassing different ways in which this determination relation might hold. First, some concepts have a "world-to-mind" direction of determination, for their determination depends on objective properties "out there". Natural kind concepts like GOLD or TIGER fit this description. Conversely, some other concepts have a "mind-to-world" direction of determination, because their determination depends partly on a linguistic community's shared conception; social kind concepts like GAME or JUICE are a case in point. Concepts 
also have a modal range: some of them, for example the concept WATER, are tied to a particular world for their individuation (they are "world-bound") and have epistemic counterparts. Others, like mathematical concepts, are tied to no particular world (they are "world-invariant") and have no epistemic counterparts. Finally, concepts have a temporal range: they are tied to common conceptions at the community level, or to institutionalized practices, that change throughout time. These distinctions have interesting implications when it comes to implementing conceptual revisions, for different strategies will be needed depending on the metasemantic features of the concept at issue.

In her article "Re-engineering knowledge: a case study in pluralist conceptual engineering" (Nado forthcoming), Jennifer Nado explores the prospects for a pluralistic revision of the knowledge concept, thus engaging in an exercise of applied conceptual engineering. As she observes, the concept of knowledge has been linked to a variety of aims and purposes; this suggests that it might be "fulfilling multiple purposes in a passable but non-optimal fashion" (p. 1). For starters, knowledge has been related to rational action, so the first task is that of engineering a concept, call it knowledge ${ }_{A C T}$, that can play the "norm of action" role. We have good prima facie reasons, Nado holds, to construct this concept as being sensitive to the standards of the knower, which may vary depending on practical interests and purposes. Secondly, knowledge has been described as the norm of assertion. The engineered concept, knowledge ${ }_{A S T}$ should - according to Nado's account - be sensitive to the standards of the asserter's audience (as opposed to the asserter's own standards). Similar considerations hold for knowledge as a norm for accurate testimony, which Nado labels knowledge $e_{T E S}$. By contrast, the knowledge concept that is customarily associated with inquiry and explanation - call it knowledge $e_{E X P}-$ had better be insensitive to subjects' epistemic standards.

Lukas Skiba, in his article "Engineering EXISTENCE?" (Skiba forthcoming) brings together the conceptual engineering debate and a recent metaontology debate, arguing that the latter can be interpreted as a conceptual engineering enterprise that would ultimately imply a form of conceptual pluralism about EXISTENCE. The starting point is higher- 
orderism, which advocates the benefits of higher-order quantification, that is, quantification in the predicate position. Such benefits pertain chiefly to the possibility of dissolving problems about the ontology of properties. Adopting higher-order quantification seems tantamount to introducing an additional concept of existence alongside the traditional one, which applies to singular objects (as opposed to properties) and relates to first-order quantification. Skiba scrutinizes the prospects for introducing such additional concept and, more broadly, for the tenability of a conceptual pluralism that encompasses both a higherorder and a first-order existence concept. The first option (called "the modest project") is to introduce higher-order existence as an analogue of first-order existence. The second option (dubbed "the ambitious project") is that of broadening the notion of existence so that it subsumes both first-order and higher-order existence. Skiba's point is that the ambitious project faces insurmountable difficulties; the supporter of higher-order existence should rest content with the modest project.

The issue of conceptual plurality as an outcome of conceptual engineering, and its impact on communication, becomes relevant in Viktoria Knoll's paper “Topics, Disputes and 'Going Meta'" (Knoll forthcoming-b). Suppose a disagreement arises between two speakers who use, respectively, the pre-revision and the post-revision version of a certain concept. Are the two speakers talking about the same subject-matter, thus having a genuine disagreement? Some recent accounts, due to Sarah Sawyer and Derek Ball, seem to license a positive answer. Yet, they require giving up the picture that a revision of concepts was carried out. In contrast with these approaches, Knoll defends what she calls the "naïve" view, to the effect that concepts were indeed revised. She suggests that the disagreeing subjects, who use the semantically diverging pre-revision and post-revision concepts, can be regarded as having a "metalinguistic negotiation", that is, a dispute that is implicitly about how to use those concepts. This rescues the intuition of disagreement while preserving the naïve view that conceptual engineering is about concepts. The naïve view - Knoll maintains - can safely stay in the game as a viable contender for Sawyer's and Ball's views, on account of its parsimony and explanatory fruitfulness. 


\section{References}

Alston, W. P. 2005. Beyond "Justification": Dimensions of Epistemic Evaluation. Ithaca: Cornell University Press.

Belleri, D. 2021. "Downplaying the Change of Subject Objection to Conceptual Engineering." Inquiry: An Interdisciplinary Journal of Philosophy. OnlineFirst: DOI: 10.1080/0020174X.2021.1908161.

Brigandt, I. 2010. "The Epistemic Goal of a Concept: Accounting for the Rationality of Semantic Change and Variation." Synthese 177 (1): 19-40.

Brigandt, I., and Rosario, E. 2020. "Strategic Conceptual Engineering for Epistemic and Social Aims." In Conceptual Engineering and Conceptual Ethics, edited by A. Burgess, H. Cappelen, and D. Plunkett. Oxford: Oxford University Press, pp. 100-124.

Burgess, A., and Plunkett, D. 2013. "Conceptual ethics I-II." Philosophy Compass, 8(12), $1091-1110$.

Burgess, A., and Plunkett, D. 2020. "On the relation between conceptual engineering and conceptual ethics." Ratio 33 (4):281-294.

Cappelen, H. 2018. Fixing language. An essay on conceptual engineering. Oxford: Oxford University Press.

Cappelen, H., and Plunkett, D. 2020. "A Guided Tour of Conceptual Engineering and Conceptual Ethics." In Conceptual Engineering and Conceptual Ethics, edited by A. Burgess, H. Cappelen, and D. Plunkett. Oxford: Oxford University Press, pp. 1-26.

Chalmers, D. 2020. "What is Conceptual Engineering and What Should it Be?" Inquiry: An Interdisciplinary Journal of Philosophy. Doi: https://doi.org/10.1080/0020174X.2020.1817141

Díaz-León, E. 2020. "Descriptive vs. Ameliorative Projects: The Role of Normative Considerations." In Conceptual Engineering and Conceptual Ethics, edited by A. Burgess, H. Cappelen, and D. Plunkett. Oxford: Oxford University Press, pp. 170186. 
Flocke, V. 2020. "How to engineer a concept." Philosophical Studies. DOI: https://doi.org/10.1007/s11098-020-01570-4

Fuš, M. 2021. Assert This: "Philosophers Are Engineers" A Study of Philosophical Engineering and Generic Judgments [Unpublished doctoral dissertation]. University of Oslo and University of St Andrews.

Haslanger, S. 2020. "Going On, Not in the Same Way." In Conceptual Engineering and Conceptual Ethics, edited by A. Burgess, H. Cappelen, and D. Plunkett. Oxford: Oxford University Press, pp. 230-260.

Isaac, M. G. 2020. "How To Conceptually Engineer Conceptual Engineering?" Inquiry: An Interdisciplinary Journal of Philosophy. DOI: https://doi.org/10.1080/0020174X.2020.1719881

Isaac, M. G. 2021. "Post-Truth Conceptual Engineering." Inquiry: An Interdisciplinary Journal of Philosophy, DOI: https://doi.org/10.1080/0020174X.2021.1887758.

Jenkins, K. 2016. "Amelioration and Inclusion: Gender Identity and the Concept of Woman." Ethics 126 (2): 394-421.

Knoll, V. forthcoming-a. "Verbal disputes and topic continuity." Inquiry: An Interdisciplinary Journal of Philosophy.

Knoll, V. forthcoming-b, "Topics, Disputes and 'Going Meta'." Inquiry: An Interdisciplinary Journal of Philosophy.

Lewis, D. K. 1983. "New work for a theory of universals." Australasian Journal of Philosophy, 61(4): 343-377.

MacFarlane, J. 2014. Assessment Sensitivity: Relative Truth and its Applications. Oxford University Press.

McKenna, R. 2017. "Pluralism about Knowledge." In Epistemic Pluralism, edited by A. Coliva and N. J. J. L. L. Pedersen (eds.). London: Palgrave Macmillan, pp. 171198.

McPherson, T. and Plunkett, D. 2020. "Conceptual Ethics and the Methodology of Normative Inquiry." In Conceptual Engineering and Conceptual Ethics, edited by A. 
Burgess, H. Cappelen, and D. Plunkett. Oxford: Oxford University Press, pp. 274303.

Nado, J. forthcoming. "Re-engineering knowledge: a case study in pluralist conceptual engineering." Inquiry: An Interdisciplinary Journal of Philosophy. DOI: https://doi.org/10.1080/0020174X.2021.1903987.

Nado, J. 2019. "Conceptual Engineering, Truth, and Efficacy." Synthese. OnlineFirst: DOI:10.1007/s11229-019-02096-x.

Nefdt, R. M. 2021. “Concepts and conceptual engineering: answering Cappelen's challenge." Inquiry, DOI: 10.1080/0020174X.2021.1926316

Pérez Carballo, A. 2020. "Conceptual Evaluation: Epistemic." In Conceptual Engineering and Conceptual Ethics, edited by A. Burgess, H. Cappelen, and D. Plunkett. Oxford: Oxford University Press, pp. 304-333.

Pinder, M. 2019. "On Strawson's critique of explication as a method in philosophy." Synthese:1-27. DOI: https://doi.org/10.1007/s11229-017-1614-6.

Podosky, P. M. 2018. "Ideology and normativity: constraints on conceptual engineering." Inquiry: An Interdisciplinary Journal of Philosophy. DOI: https://doi.org/10.1080/0020174X.2018.1562374.

Prinzing, M. 2017. “The Revisionist's Rubric: Conceptual Engineering and the Discontinuity Objection." Inquiry: An Interdisciplinary Journal of Philosophy 61 (8): $854-880$.

Richard, M. 2020. "The A-project and the B-project." In Conceptual Engineering and Conceptual Ethics, edited by A. Burgess, H. Cappelen, and D. Plunkett. Oxford: Oxford University Press, pp. 358-378.

Richardson, K. 2020. "Grounding Pluralism: Why and How." Erkenntnis 85 (6):1399-1415.

Sawyer, S. 2020. "Truth and objectivity in conceptual engineering." Inquiry: An Interdisciplinary Journal of Philosophy 63 (9-10):1001-1022.

Sawyer, S. forthcoming. "Concept Pluralism in Conceptual Engineering." Inquiry: An Interdisciplinary Journal of Philosophy. 
Scharp, K. 2013. Replacing Truth. Oxford: Oxford University Press.

Sider, T. 2011. Writing the book of the world. Oxford: Oxford University Press.

Simion, M. 2018a. "Epistemic Trouble for Engineering 'Woman'." Logos and Episteme 9 (1):91-98

Simion, M. 2018b. "The 'should' in conceptual engineering." Inquiry: An Interdisciplinary Journal of Philosophy 61 (8):914-928.

Simion, M., and C. Kelp. 2020. "Conceptual Innovation, Function First.” Nô̂s. 54 (4):985-1002. DOI: doi:10.1111/nous.12302.

Skiba, L. forthcoming, "Engineering EXISTENCE?” Inquiry: An Interdisciplinary Journal of Philosophy.

Strawson, P. F. 1963. "Carnap's View on Constructed Systems Versus Natural Languages in Analytic Philosophy." In The Philosophy of Rudolf Carnap, edited by Paul Schilpp. La Salle: Open Court, pp. 502-518.

Thomasson, A. 2020. "A Pragmatic Method for Conceptual Ethics." In Conceptual Engineering and Conceptual Ethics, edited by A. Burgess, H. Cappelen, and D. Plunkett. Oxford: Oxford University Press, pp. 435-458.

Wright, C. 1992. Truth and Objectivity. Harvard: Harvard University Press. 